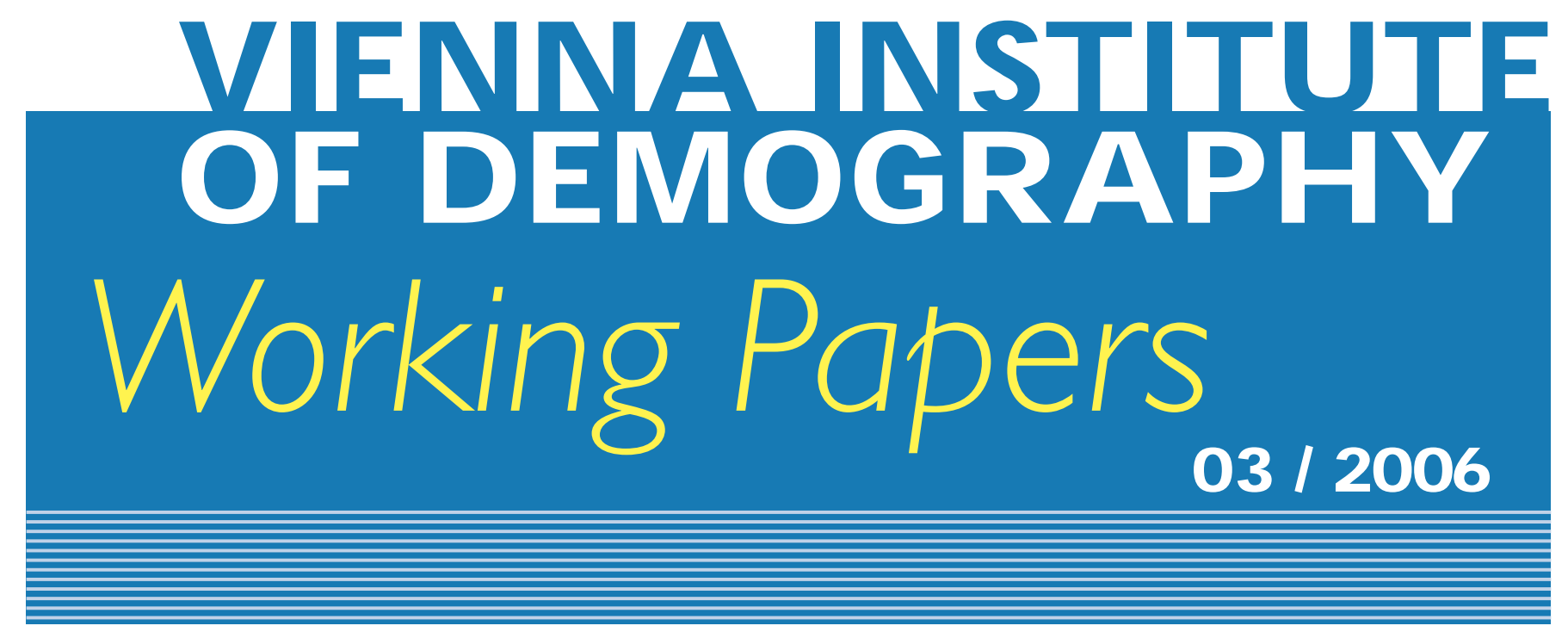

Franz Schwarz

\title{
Behavioral Explanation for Educational Health and M ortality Differentials in Austria
}

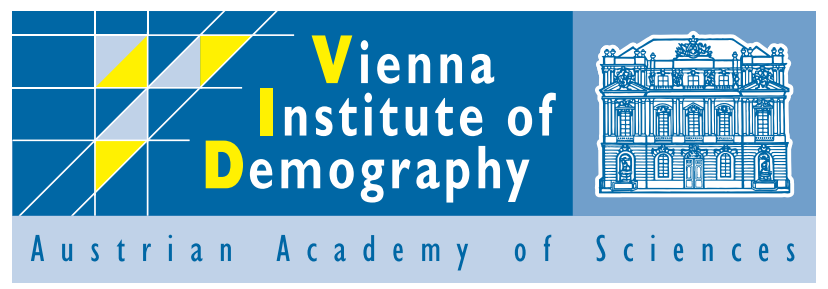

Vienna Institute of D emography A ustrian A cademy of Sciences

Prinz Eugen-Straße 8-10 · A-1040 Vienna · A ustria

E-Mail: vid@ oeaw.ac.at

W ebsite: www.oeaw.ac.at/vid 


\begin{abstract}
The present study examines the health behavior of more than 30,000 individuals aged 2574 in Austria, using education as an indicator of socioeconomic status. Of particular interest is the magnitude of the educational disparities in health behavior between hypothetical most and least educated, measured by the Relative Index of Inequality. The findings show that education has a great positive impact on the extent to which a person lives a healthy lifestyle with regard to diet, physical activity, and smoking. Furthermore, the prevalence of overweight decreases significantly with any increase in education, and people with more education are also much more likely to get their periodical vaccinations.
\end{abstract}

\title{
Keywords
}

Health behavior, Lifestyle, Education, Socioeconomic, Differentials, Inequalities, Austria

\section{Author}

Franz Schwarz is research scientist at the Vienna Institute of Demography, Austrian Academy of Sciences. Mailing Address: Vienna Institute of Demography, Prinz Eugen Strasse 8, 2nd floor, 1040 Vienna, Austria. E-mail: franz.schwarz@oeaw.ac.at. Phone: +43 1-515-81-7720. Fax: +43 1-515-81-7730. 


\title{
Behavioral Explanation for Educational Health and Mortality Differentials in Austria
}

\author{
Franz Schwarz
}

\section{Introduction}

Why do people from a higher socioeconomic class on average live longer? Why are they usually healthier than those from a lower class? International and Austrian studies have shown that mortality rates are consistently higher among those on the lower end of the socioeconomic scale than among those on the higher end (i.e. Kitagawa and Hauser 1973, Kunst 1997, Valkonen 2001, Mackenbach 2006). In Austria, the magnitude of these inequalities is substantial and affects both men and women, with a greater impact on men (Doblhammer 1997, Schwarz 2006a). Among the Austrian population, differentials were found for most but not all important causes of death (Schwarz 2006a). Over the last few decades, all-cause and cause-specific inequalities in mortality have even further increased in Austria (Doblhammer et al. 2005, Schwarz 2005, Rau et al. 2006, Schwarz 2006b), as well as in many other industrialized countries (i.e. Pamuk 1985, Preston and Elo 1995, Mackenbach 2003, Blakely et al. 2005).

A commonly used framework offers four explanations for health and mortality differentials (Townsend and Davidson 1982, Davey Smith 1990, Macintyre 1997): According to the selection hypothesis, a lower socioeconomic status does not necessarily mean that people are less healthy and will thus die earlier, but rather they have occupy a lower socioeconomic position precisely because of their poor health. Nevertheless, health selection seems to be less relevant than causative factors (Davey Smith et al. 1994). The cultural and behavioral explanation, on the other hand, suggests that health-damaging behaviors are distributed differentially across social classes. Another hypothesis - the material and structural - suggests that the lower social classes may also be exposed to health damaging-material living conditions as well as physiological and psychological syndromes associated with their socioeconomic position, with all of them affecting their health and mortality. A fourth hypothesis states that the gradients observed are an artifact of measurement.

The present study looks into the behavioral explanation for socioeconomic disparities in health and mortality. It examines the health behavior of more than 30,000 individuals in Austria, using education as an indicator for their socioeconomic status. Of particular interest is the magnitude of the educational disparities in health behavior between hypothetical most and least educated, measured by the Relative Index of Inequality. Health behavior in this study is defined by the following: a healthy diet; physical activity; regular vigorous physical exercise; overweight; smoking; and vaccination against polio, tetanus, meningitis caused by ticks, and influenza. ${ }^{1}$ While diet, exercise, overweight, and smoking

\footnotetext{
${ }^{1}$ No reliable data was available on alcohol consumption.
} 
refer to particular behaviors that more or less directly affect health, vaccination behavior explains a commitment to use preventive health-care measures to avoid disease.

The effect of education on health behavior is examined via logistic regression. The variable "education" in quantified so that the exponential of the regression coefficient results in the Relative Index of Inequality (RII). Hence, the RII in this application can be interpreted as the odds ratio between the hypothetically least and most educated people. Age-specific analyses, however, first provide an overview of the educational differentials in health behavior.

\section{Possible Explanations for Social Gradients in Mortality}

The probably most commonly used framework explaining mortality differentials is based on the hypotheses introduced in the so-called Black Report, a study on social inequalities in health and mortality in Britain (Townsend and Davidson 1982, Davey Smith 1990, Macintyre 1997). This landmark report provides four possible explanations:

1. The artifact theory states that the gradients are an artifact of measurement.

2. The selection hypothesis, implies that people are not less healthy because of their lower socioeconomic status, but rather that they have a lower socioeconomic position because of their poor health.

3. The material and structural hypothesis suggests that persons in a lower social class may also experience health-damaging material living conditions as well as physiological and psychological features associated with their socioeconomic position that affect health.

4. Lastly, the cultural and behavioral hypothesis suggests that health-damaging behaviors are distributed differentially across social classes.

Table 1: Versions of possible explanations for the social class gradient in health and mortality

\begin{tabular}{lll}
\hline \multicolumn{1}{c}{ Possible Explanation } & \multicolumn{1}{c}{ Hard Version } & \multicolumn{1}{c}{ Soft Version } \\
\hline Artifact & $\begin{array}{l}\text { No relation exists between class and } \\
\text { mortality; it is purely an artifact of } \\
\text { measurement. }\end{array}$ & $\begin{array}{l}\text { The magnitude of observed class } \\
\text { gradient will depends on the } \\
\text { measurement of both class and health. }\end{array}$ \\
Natural/Social Selection & $\begin{array}{l}\text { Health determines class position, } \\
\text { therefore, class gradients are morally }\end{array}$ & $\begin{array}{l}\text { Health can contribute to achieve class } \\
\text { position and help to explain the } \\
\text { observed gradients. }\end{array}$ \\
neutral and thus explained away. & $\begin{array}{l}\text { Material/physical living conditions } \\
\text { associated with class structure entirely } \\
\text { explain class gradients in health. }\end{array}$ & $\begin{array}{l}\text { Physical and psychological features } \\
\text { associated with class structure influence } \\
\text { health and contribute to the gradients } \\
\text { observed. }\end{array}$ \\
& $\begin{array}{l}\text { Health-damaging behaviors freely } \\
\text { chosen by individuals in different social differentially distributed across social } \\
\text { classes explain away social class } \\
\text { classes and contribute to the gradients }\end{array}$ & $\begin{array}{l}\text { Health-damaging behaviors are } \\
\text { observed. }\end{array}$ \\
\hline
\end{tabular}

Source: Macintyre (1997)

Macintyre (1997) has reviewed these explanations, and discussed a "hard" and a "soft" version of possible explanations for social-class differences in health and mortality, 
summarized in Table 1 . While the hard versions make a respective explanation entirely responsible for the social gradients in health and mortality, the more reasonable soft versions suggest that each explanation can contribute to the differentials. The hard version of the artifact explanation suggests that there is no real relationship between social class and health; the relationship between them is an artifact of measurement with little causal significance. The soft version of the artifact explanation, however, does acknowledge that any measurement of social class and health might influence, to a greater or lesser extent, magnitude and trends in observed health inequalities. In view of the fact that over the past few decades plentiful research has already revealed social class differences in health and mortality, the artifact explanation better serves to create awareness of such possible measurement problems.

Various studies have shown the health-damaging effects of smoking, vitamin and minerals deficiencies, low fiber, high fat and salt consumption, lack of physical activity and other health-damaging behaviors. In this regard, the hard version of the cultural/behavioral explanation states that class gradients in health and mortality are completely due to (or 'explained away' by) health-damaging behaviors. The soft version, on the other hand, suggests that certain health-damaging behaviors are distributed differently across social classes but that this fact simply contributes to social class gradients in health and mortality. It says that unfavorable health behaviors are more prevalent among the lower classes; as a result, among disadvantaged groups, one can observe poorer health and lower life expectancy. Accordingly, the Black Report recommends taking action through preventive and educational measures promoting good health.

The materialist/structural explanation concerns economic factors associated with social class that lead to social-class gradients in health and mortality. It refers to the importance of prosperity and well-being, which is mainly determined by a person's occupational position. The materialist/structural explanation points out that healthinfluencing factors - such as quality of housing, occupational risks, job security and stability, job satisfaction, and physical and mental strain - are distributed differently across social classes and can contribute to the observed gradients in health and mortality. The hard version of the materialist/structural explanation suggests that material and physical conditions associated with a person's social position provide a complete explanation for class gradients in health and mortality. The soft version includes, besides physical factors, psychological features and living conditions that influence health and contribute to the gradients observed.

The natural/social selection theorem has its roots in the Darwinian theory of natural selection. It means that the basis of selection is health-i.e. physical strength, vigor, and abilities - which enables a person to keep or attain a place in society. The hard version of this take on the theory of natural selection implies that health determines class position. Here, class gradients in health and mortality are a natural phenomenon, i.e. based on biology, with neither inequity nor unfairness, or in other words, morally neutral and thus explained away. The soft version of this natural/social selection, on the other hand, suggests that health does contribute to social position to a greater or lesser extent. For instance, those in poor health during childhood may suffer in terms of educational 
achievements; and in adulthood, they may be excluded from certain jobs because of being less educated and in poor health. However, Davey Smith et al. (1994) concludes that natural selection can be responsible for only a small part of socioeconomic disparity in mortality. It is more likely that factors can simultaneously affect a person's socioeconomic position as well as their health and mortality. For instance, a person whose parents come from a higher social class, who performs well at school and who displays certain physiological and mental characteristics will have it easier when trying to move up in society as an adult. Nonetheless, these conditions and predispositions also affect their lifestyle and health-related behaviors (Valkonen 2001). Marmot et al. (1998) also suggest that a set of both early and current life circumstances cumulatively contribute toward explaining why people of lower socioeconomic status have worse health and lower psychological well-being.

The main groups of factors explaining socioeconomic differentials in health and mortality-behavior, material factors, and psychosocial factors - are interlinked, as is shown in Figure 1. For instance, material disadvantages associated with lower socioeconomic status may partly affect psychosocial factors as well, and together result in a lack of physical exercise, an unhealthy diet, or substance abuse such as alcoholism or smoking.

Figure 1: Explanatory diagram of factors interlinking socioeconomic status and health

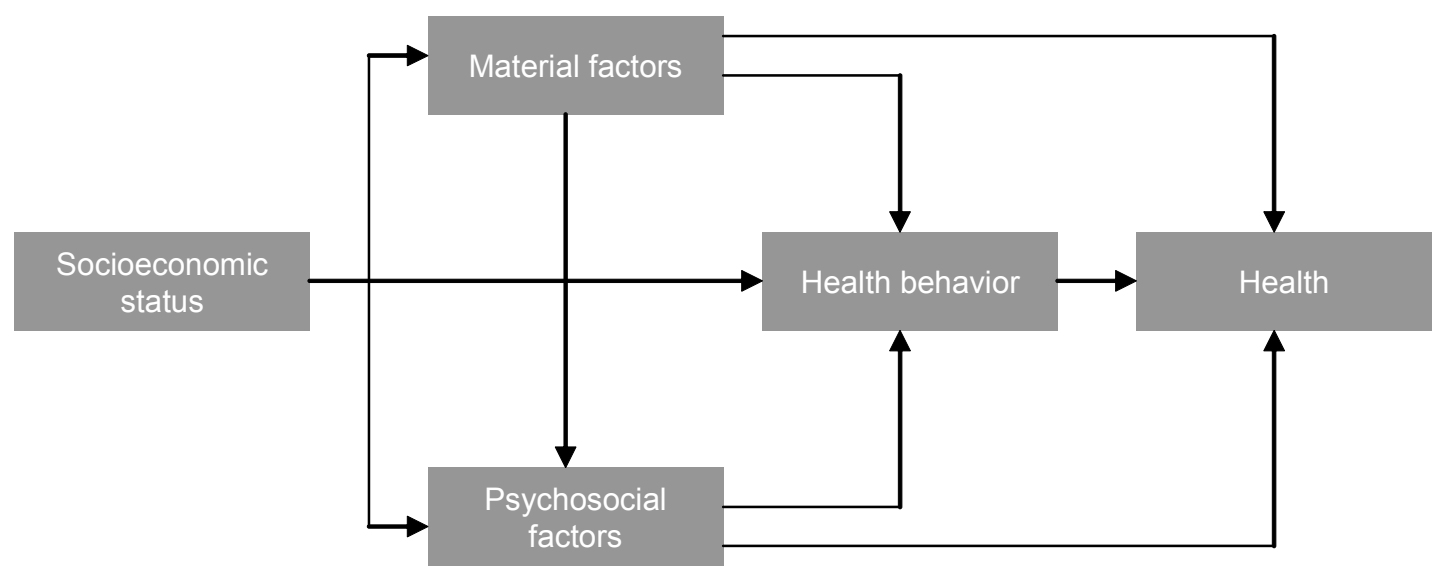

Source: Mackenbach (2006)

\section{Data and Methods}

The data source for the analysis is the Austrian Microcensus 1999-03 that included a supplementary questionnaire on health-related issues. The Austrian Microcensus is a household panel survey carried out quarterly in one percent of all Austrian dwellings. On a quarterly basis, one eighth of the sample is replaced. The survey consists of a mandatory basic program and a voluntary special program. The basic program collects data on the social, vocational and educational status of the respondents. In September 1999, the optional special program consisted of a survey on health behavior, health status, and use of health-care services. Out of the 58,745 people who responded to the mandatory basic 
program, 45,572 of them responded to at least one question from the voluntary special program. The final dataset used for the analyses in this study comprises the population aged 25-74 and contains records on approximately 30,000 individuals who responded to the health-related questions.

Table 2: Variables with percentages and number of cases among males and females aged 25-74 years, Austria, 1999

\begin{tabular}{|c|c|c|c|c|c|}
\hline \multirow{2}{*}{ Variable } & \multirow{2}{*}{ Levels } & \multicolumn{2}{|c|}{ Males } & \multicolumn{2}{|c|}{ Females } \\
\hline & & Percentage & Number of cases & Percentage & Number of cases \\
\hline \multirow[t]{2}{*}{ Healthy diet } & Yes & 44.3 & 6037 & 55.8 & 8478 \\
\hline & No & 55.7 & 7595 & 44.2 & 6708 \\
\hline \multirow[t]{2}{*}{ Physical activities } & Yes & 57.8 & 6868 & 58.2 & 7162 \\
\hline & No & 42.2 & 5018 & 41.8 & 5137 \\
\hline \multirow{2}{*}{$\begin{array}{l}\text { Regularly vigorous physical } \\
\text { exercise }\end{array}$} & Yes & 24.2 & 3181 & 16.4 & 2406 \\
\hline & No & 75.8 & 9983 & 83.6 & 12286 \\
\hline \multirow[t]{2}{*}{ Overweight $(\mathrm{BMI}>25)$} & Yes & 57.0 & 7895 & 39.7 & 6069 \\
\hline & No & 43.0 & 5950 & 60.3 & 9233 \\
\hline \multirow[t]{2}{*}{ Smoking } & Yes & 29.5 & 4117 & 20.5 & 3178 \\
\hline & No & 70.5 & 9856 & 79.5 & 12333 \\
\hline \multirow{2}{*}{$\begin{array}{l}\text { Vaccination polio \& tetanus } \\
\& \text { meningitis }\end{array}$} & Yes & 40.6 & 5018 & 39.2 & 5508 \\
\hline & No & 59.4 & 7349 & 60.8 & 8540 \\
\hline \multirow[t]{2}{*}{ Influenza vaccination } & Yes & 13.1 & 1755 & 13.4 & 1993 \\
\hline & No & 86.9 & 11608 & 86.6 & 12908 \\
\hline \multirow[t]{3}{*}{ Education } & Low & 20.9 & 2997 & 39.3 & 6247 \\
\hline & Middle & 58.6 & 8383 & 43.4 & 6893 \\
\hline & High & 20.5 & 2936 & 17.3 & 2758 \\
\hline \multirow[t]{5}{*}{ Age group } & {$[25,35)$} & 19.8 & 2840 & 19.1 & 3035 \\
\hline & {$[35,45)$} & 26.3 & 3763 & 26.1 & 4145 \\
\hline & {$[45,55)$} & 21.5 & 3071 & 20.1 & 3198 \\
\hline & {$[55,65)$} & 18.7 & 2681 & 18.3 & 2908 \\
\hline & {$[65,75)$} & 13.7 & 1961 & 16.4 & 2612 \\
\hline
\end{tabular}

Table 2 provides an overview of the health-related and demographic variables used in this study. All analyses were carried out separately for males and females because they differ considerably in their health behavior. In the health survey, participants were asked whether or not they follow a healthy diet and whether they are engaged in physical activities to stay fit and prevent disease. In an additional question about physical exercise, participant were asked how many days per week they engaged in hard aerobic activity that made them sweat in such activities as jogging, biking, sports, or other aerobic activities in their leisure time. All those who answered the question about physical activity 
affirmatively, and additionally did something physical that made them sweat at least twice a week were defined as exercising regularly.

To calculate the Body Mass Index (BMI), respondents were asked about their height and weight. In this study, all those with a BMI $>25$ were considered overweight - as defined by the World Health Organization (WHO)

Smoking cigarettes was another issue included in the survey. In this study, all those who smoked at least one cigarette per day were defined as smokers; while those who never smoked, quit smoking, or smoke only occasionally were alternatively classified as nonsmokers.

The survey also collected information on the four most common vaccinations in Austria. The immunizations against polio, tetanus, and meningitis caused by ticks are strongly recommended regardless of age and health status. Hence, these vaccinations are considered together as one dichotomous variable, with the categories "vaccinated" or "not vaccinated" against all three. Immunization against influenza is examined separately, since in Austria it is strongly recommended only for people who are immuno-compromised and for the elderly.

To assess social inequalities, "educational level" is used as an indicator of social stratification. Education remains virtually constant throughout adulthood and is available to all adults, whether they are currently in the labor force or not. Furthermore, education is influenced less by health problems that develop in adulthood than by other socioeconomic indicators (Preston and Elo 1995, Davey Smith 1998). The levels of education in this study are as follows:

1. Low: Compulsory education (8-9 years of schooling)

2. Middle: Apprenticeship or vocational school (10-11 years of schooling)

3. High: Upper-secondary school that ends with the Matura (university entrance degree), a diploma from an academy or prep school, or a college or university degree (12 or more years of schooling).

This study uses logistic regression to investigate the association between health behavior and education and, at the same time, to standardize for age. In the binary logistic regression model, the dependent variable is an indicator of the presence or absence of a condition that can be coded with 0 or 1 . With regard to prevalence proportions, the dependent variable has two outcomes, namely 0 for a positive and 1 for a negative. The logit model predicts the proportion $\pi(x)$ of those with certain characteristics $x$, i.e. the proportion of those who are overweight or for those with a certain level of education and of a certain age. However, here the choice is made to estimate the transformation of $\pi$ rather than $\pi$, in order to ensure that response probabilities remain strictly between zero and one. This transformation is called 'logit transformation' or 'log odds',

$$
\operatorname{logit}[\pi(x)]=\ln \left[\frac{\pi(x)}{1-\pi(x)}\right] .
$$

The logistic regression equations in this study is:

$$
\operatorname{logit}[\pi(x)]=\beta_{0}+\beta_{1} \text { educat }+\beta_{2} \text { age }_{j} .
$$


The covariate "age" in equation (2) is categorical with 10-year age groups, ranging from age 25-74, with a dummy variable for each category. The covariate "education" is quantified by arranging the hierarchical educational categories from lowest to highest and computing the cumulative proportionate distribution of the population. As a result, each group covers a range proportional to its population size, on a scale from 0 to 1 . The midpoints of the percentile range of the respective education groups are then used as the parameter-value for the quantitative variable "education". For example, if the lowest education group covers $20 \%$ of the population, then a value of $0.1-$ which is the midpoint of the $20 \%$ - is assigned to the category "low education". If the next highest category comprises $30 \%$ of the population, the value $0.2+0.3 / 2=0.35$ is assigned to that category, and so on. This quantification approach assumes a linear relationship - or in the logit model a logistic-linear one, respectively-between education and health behavior. A similar approach was used by Kunst (1997), who used the Poisson regression to examine educational mortality differentials. The antilog of the regression coefficient $\beta$ of the quantitative variable "education" is called the Relative Index of Inequality (RII), $\mathrm{RII}=\exp (\beta)$. The RII can be interpreted as the odds ratio between the hypothetically least $($ education $=0)$ and mostly highly educated (education $=1){ }^{2}$

The basic concept of this inequality measure was introduced by Preston, Haines and Pamuk in 1981 (c.f. Pamuk 1985, Preston and Elo 1995). Pamuk (1985) introduced the Relative Index of Inequality that was later further developed by Kunst and Mackenbach (1994) to measures the rate ratio of the hypothetically most disadvantaged to the most advantaged. The RII has two major advantages over simple rate ratios. It explains inequalities with a single value that comprises all categories at once. Furthermore, the RII takes into account the relative position of the various educational groups, which is very useful both when populations differ in their distribution with respect to the inequality variable or when the distribution changes over time. In Austria, for example, the educational distributions of men and women differ substantially. For the present application the RII services more to estimate the differentials between extreme groups. It overcomes the problem that the level of education "high" includes a wide range of levels. Not combining these educational levels would result in huge statistical variation for each of the actual level. The category "low education", on the other hand, includes a vast percentage of people - as Table 1 shows. Even though eight years of schooling are compulsory, there are assumedly different levels of education within the category "low". However, the applied approach with the RII works only with the assumption of a linear relationship between education and health behavior. For that reason, descriptive analysis for the educational levels low to high examine first whether at each point in the hierarchy the percentage of people living a healthy lifestyle is higher than those below them and lower than the percentage above them - and whether this applies to all age groups.

\footnotetext{
${ }^{2}$ In terms of proportions $p$ the odds-ratio opposes the odds, $p /(1-p)$, of two groups: OR $=\left[p_{1} / 1-p_{1}\right] /\left(p_{0} /\left(1-p_{0}\right)\right]$. An odds-ratio of one means equal chances for both groups. The further the odds ratio departs from one, the greater the effect will be.
} 


\section{Results}

\subsection{Education and Health Behavior by Age}

The following figures show age-education-specific analyses of the variables "healthy diet", "physical activity", "regular vigorous physical exercise", "overweight", "smoking", the combined variable "vaccination against polio, tetanus and tick meningitis", and "influenza vaccination". Figure 2 shows that a higher educational level is, the greater is the percentage of people who declared to eat healthy, regardless of age or gender. The three lines for the different educational levels run almost parallel over the entire age span, with a difference of around $10-15 \%$ between categories. People at each step of the hierarchy are less likely to be health-conscious about their diet than are those above them. Apart from less educated males up to age 54, the percentages on watching one's diet increase slightly with age for all educational levels.

Figure 2: Percentage of people who stated that they follow a healthy diet, by age and level of education, Austria, 1999
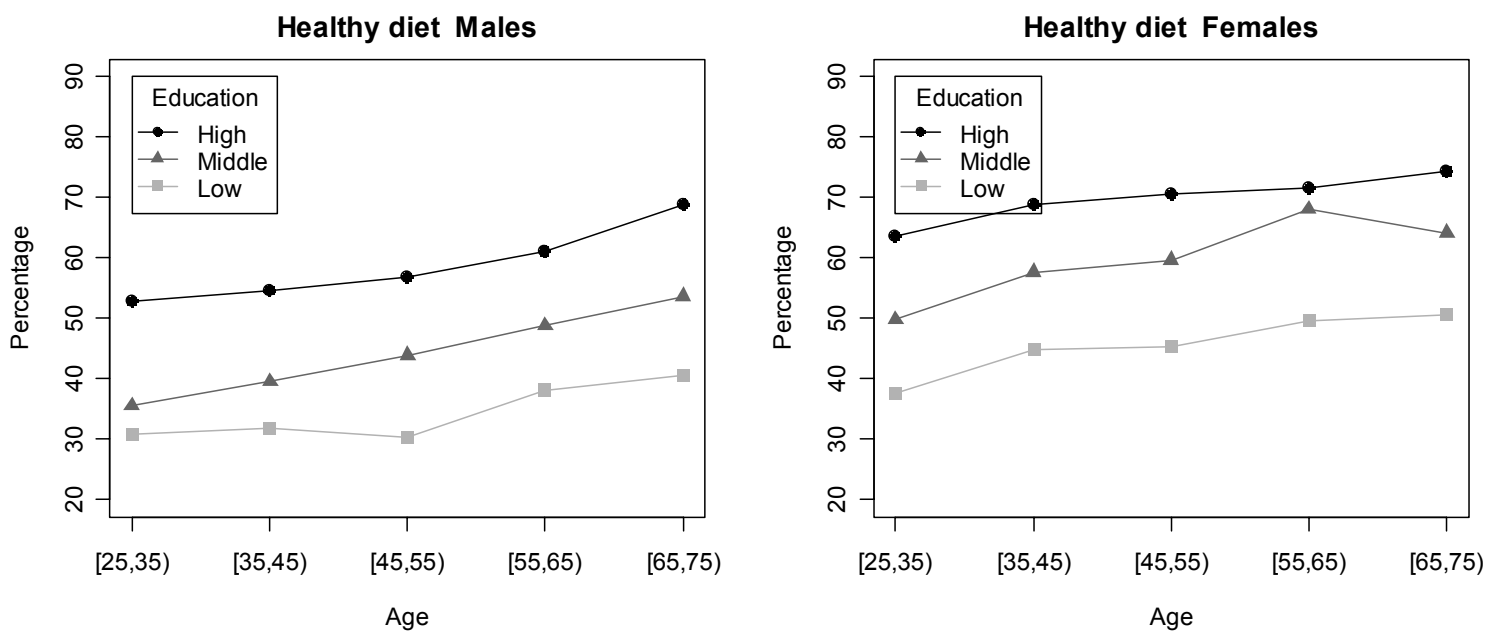

A similar outcome was found for physical activity, as shown in Figure 3. Among more highly-educated males, around $75 \%$ initially declared themselves to be involved in physical activities to stay fit and prevent disease, while the figures were only around $60 \%$ and $40 \%$ among the moderately and less educated, respectively, regardless of gender. The percentages remained almost constant over all age groups. 
Figure 3: Percentage of people who indicated that they engage in physical activity, by age and level of education, Austria, 1999
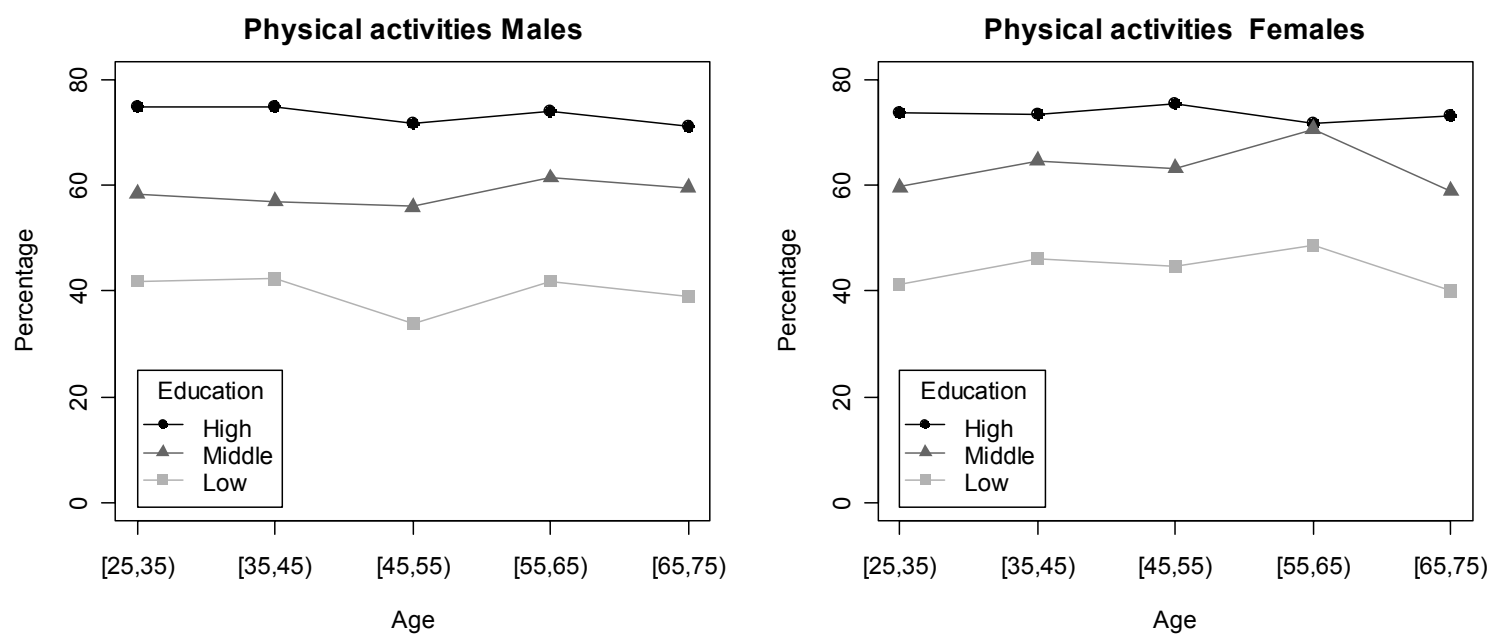

Figure 4: Percentage of people engaged in vigorous physical exercise, by age and level of education, Austria, 1999
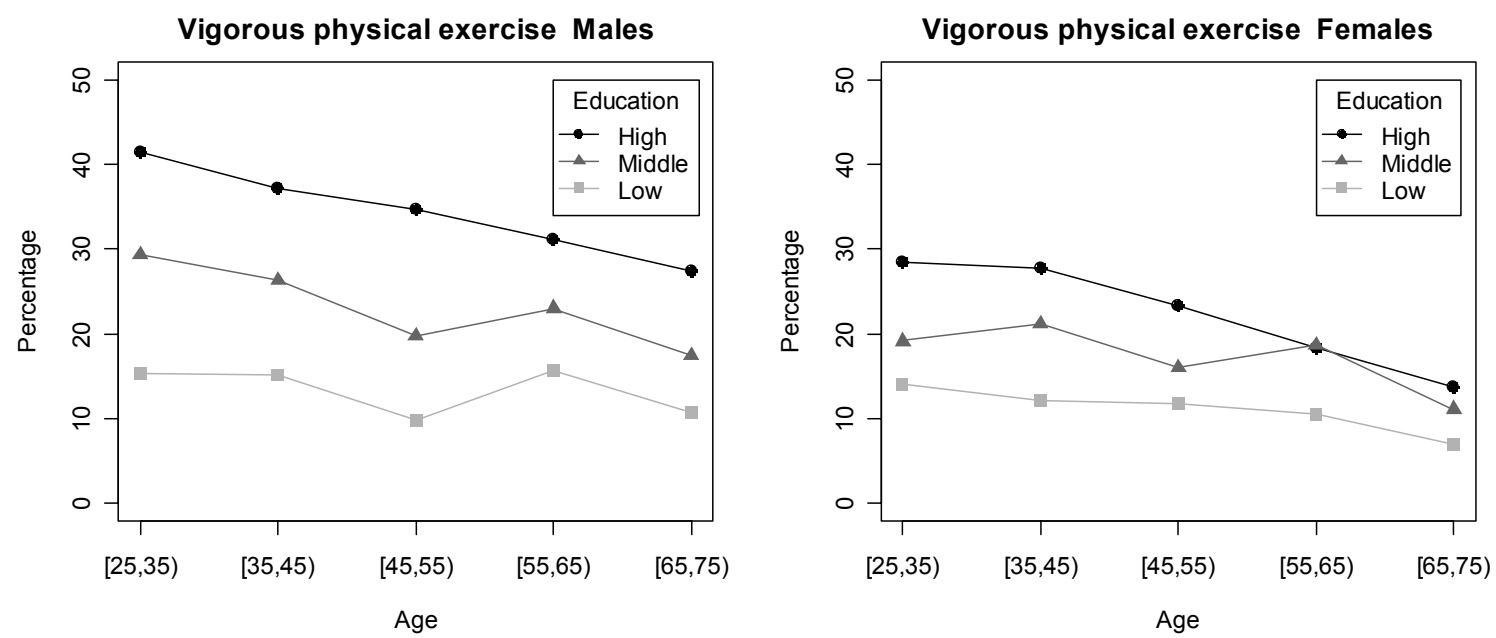

A completely different picture emerges when it comes to regular vigorous physical exercise (Figure 4). Most apparent are both the decreasing differentials and the decreasing prevalence proportions with age. With increasing age, people become increasingly frail, which may result in a lower proportion of those who are able to carry out vigorous activities. Furthermore, a systematic selection of robust individuals is most likely the reason for diminishing differentials. For instance, among those with favorable health behaviors and less stress and strain, people who are in more delicate health may also survive longer. However, among those with unfavorable health behaviors and more demands in terms of stress and strain, only the strongest may survive. As a result, differentials will diminish. The same effect was observed with male mortality differentials (Schwarz 2006a).

Figure 5 shows the percentage of overweight individuals by age and level of education. Since overweight is mainly the physiological consequence of excessive eating and sedentary behaviors, it can also be seen as an indicator of health behavior. Among 
men, the greatest differentials for overweight were observed at a younger age. With increasing age, the percentage of overweight people will rise, but the differentials will decline. Only small differences in prevalence proportions between the least and moderately educated were observed, while great differentials could be found between moderately and highly educated men. Among females, the lines run almost parallel over the entire age span, with a difference of around $5 \%$ between the moderately and highly educated, and a difference of about $10 \%$ between the less and moderately educated.

Figure 5: Percentage of overweight people (bmi $\geq 25)$, by age and level of education, Austria, 1999
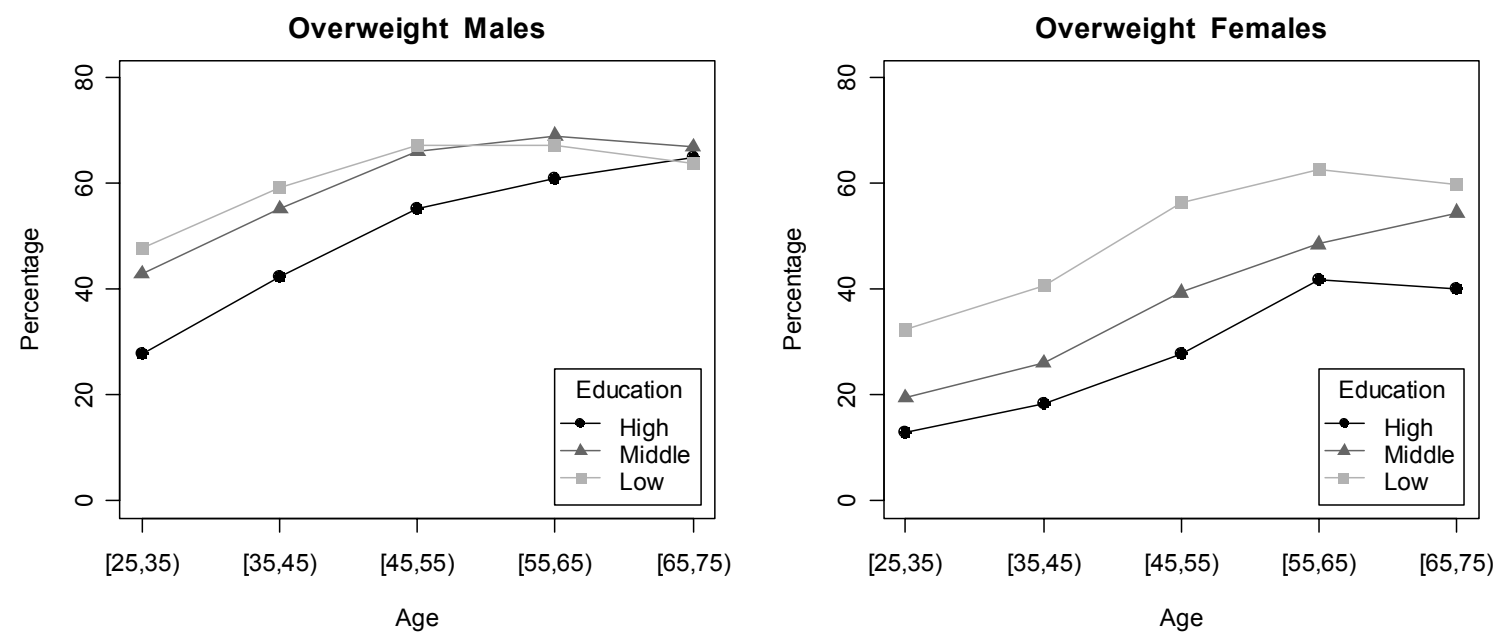

With regard to smoking, Figure 6 shows that both differentials and prevalence proportions decrease with age. Among males, around 50\% of those with the least education, $42 \%$ of the moderately educated and $27 \%$ of the highly educated initially declared that they smoke cigarettes on a daily basis. However, for the age group 60-74, the proportion of male smokers fell in a range of just $9-17 \%$. These diminishing differentials are again likely to be the result of a systematic selection of robust individuals. The general decline in proportions with age most probably occurs for two reasons: a cohort and an age effect. For one, the cohort effect suggests that the percentage of new smokers among young people has increased over the past few decades, resulting in higher prevalence proportions for young smokers. The second reason concerns higher mortality among smokers. Those who smoke will die sooner, so therefore the proportion of smokers will decline with age. Among females, the higher their level of education, the more substantially higher their prevalence rates will initially be. The differentials decline with age up to the age group 4554, at which point the differentials reverse. For females older than that, higher prevalence proportions with an increasing level of education were observed. 
Figure 6: Percentage of people who indicated that they smoke every day, by age and level of education, Austria, 1999
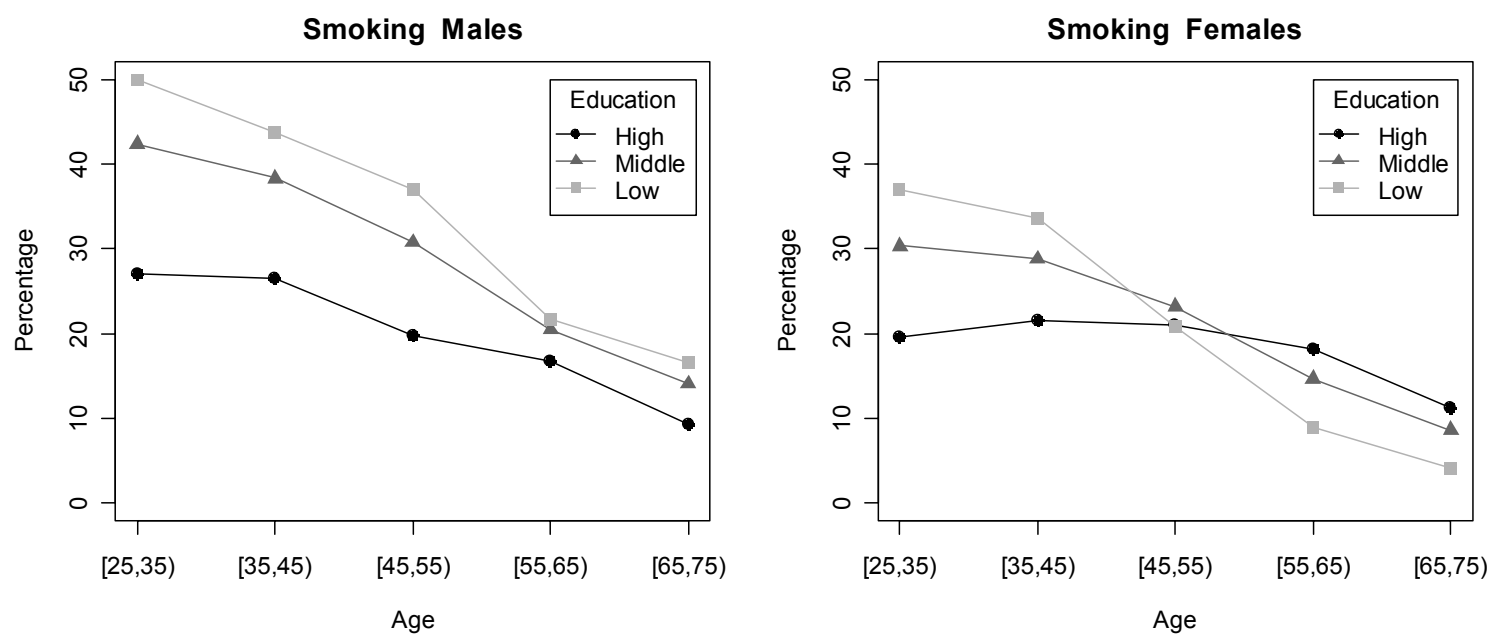

Vaccinations are an important measure when it comes to preventing some very dangerous diseases. For the present study, however, vaccination behavior serves rather as an indicator of health behavior in that it can help determine how much people care about their health. As Figure 7 shows, the percentage of those who stated that they had been vaccinated against polio, tetanus and tick meningitis increased the higher the person's level of education. Among males, the lines run parallel with almost the same distance between educational groups. For the youngest age group, only $35 \%$ of the least educated males were immunized against these three diseases; while among the most educated, the figure was almost $60 \%$. Among females, the distance of the prevalence proportions between the highly and moderately educated is narrower than between the moderately and the less educated among the younger age groups. For both sexes and all educational groups, the percentages decline slightly with age.

Figure 7: Percentage of people who said that they had been vaccinated against polio, tetanus and tick meningitis combined, by age and level of education, Austria, 1999
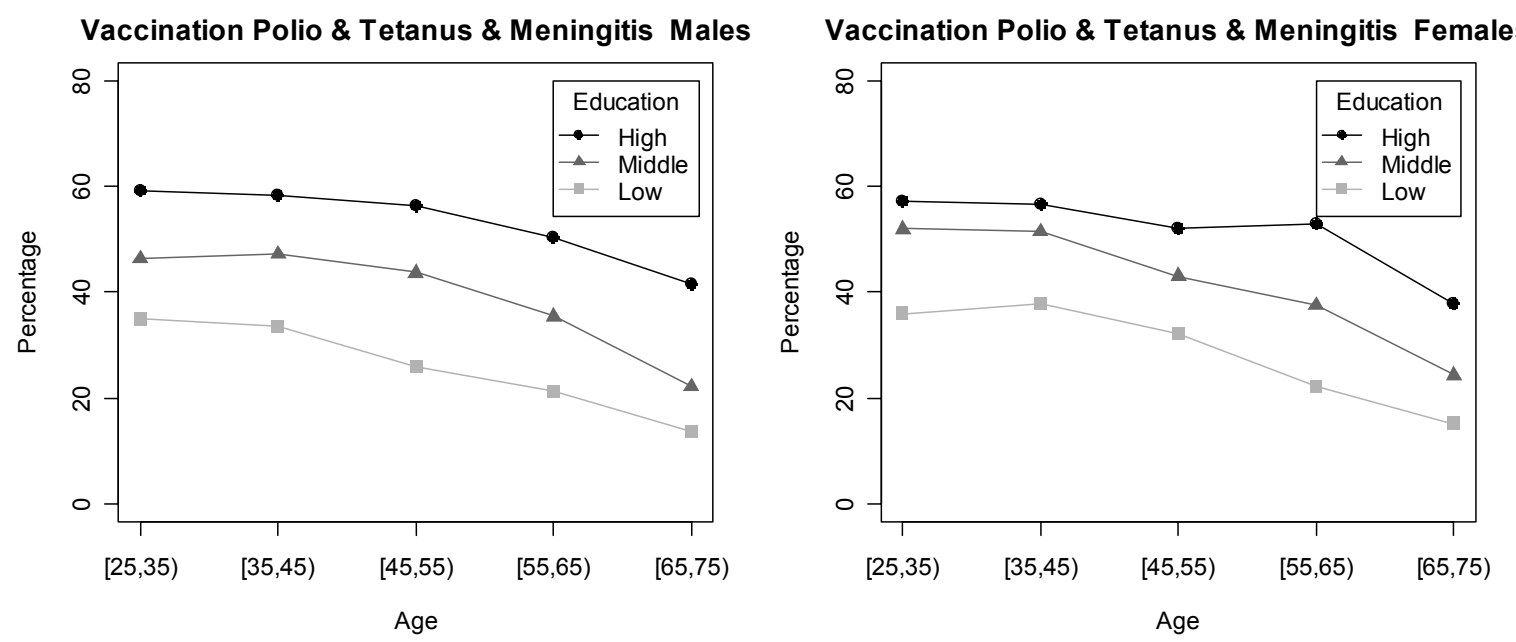
Figure 8: Percentage of people who stated that they had been vaccinated against influenza, by age and level of education, Austria, 1999
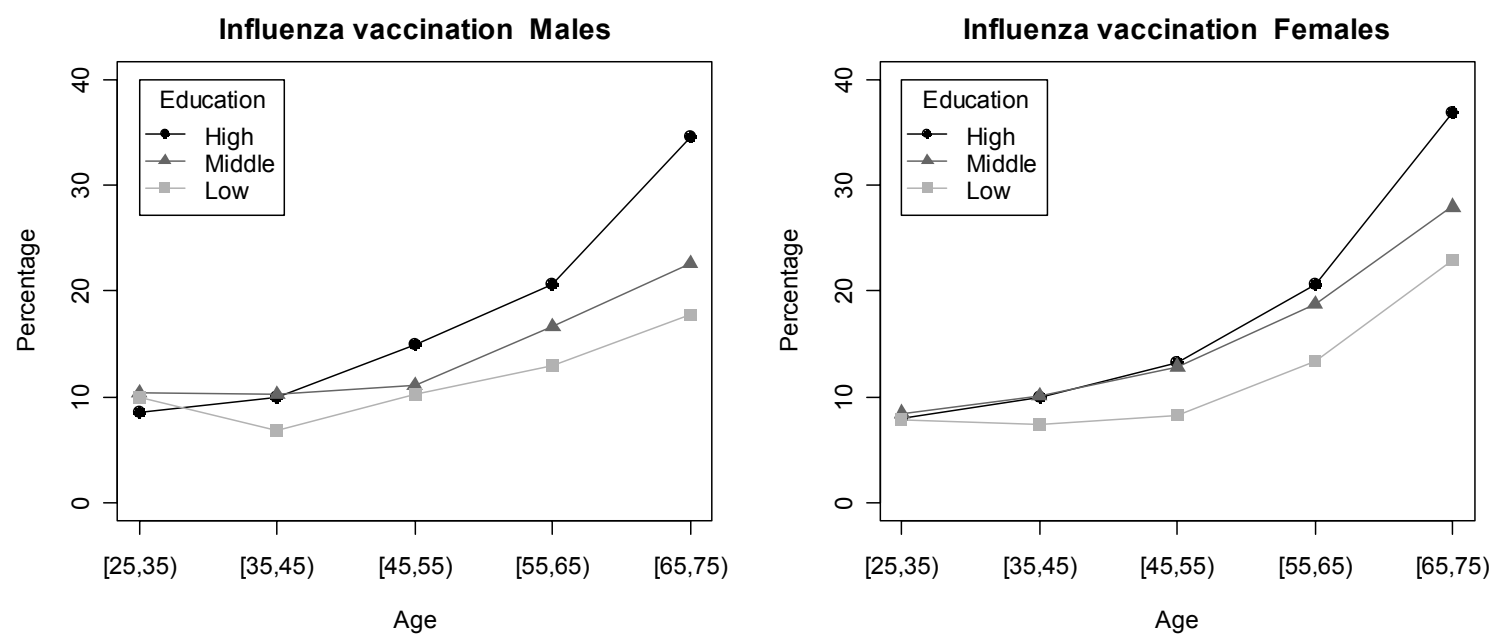

An entirely different outcome was observed for flu shots. Figure 8 shows that the differentials increase with age. While for the younger age groups no clear differences could be found, $35 \%$ of the highly educated males aged $65-74$ and $18 \%$ of the less educated males of the same age stated that they got their flu shot. Among females, the figures were $37 \%$ and $23 \%$, respectively. The generally increasing prevalence rate was to be expected, since influenza immunization is usually recommended for immune-deficient individualsfor instance, those with diabetes mellitus - and to the elderly.

To sum up, Figure 2 to Figure 8 have shown that great educational differentials are apparent for all the variables observed. People at each step on the educational hierarchy are less likely to live a healthy lifestyle than are those above them, with roughly equal distances between the groups.

\subsection{Differentials between the Hypothetically Most and Least Educated}

Table 3 shows odds ratios high versus low educational level, as well as middle versus low level, and the Relative Index of Inequality (RII) for health-behavior variables among males and females ages 25-74 adjusted for age. The RII can be interpreted as the odds ratio between the hypothetically most and least educated. The farther the RII departs from the value "one", the greater the disparity will be.

The RII for the variable "healthy diet" among men is 3.82 , which means that the most educated are 3.82 times more likely to eat healthy than are the hypothetically least educated. Among women, the RII is higher, at 4.36. The odds ratio for the high vs. low educated, on the other hand, is around 2.8, for both males and females. The RIIs between males and females are different because the RII takes into account the middle level of education, and additionally, the educational distributions - which differ considerably between the sexes.

The greatest disparities were observed for physical activity, with an RII of 6.55 for males and 6.22 for females. In contrast, the differentials for vigorous physical exercise are 
much lower (4.53 and 3.47, respectively). However, the lower differentials here are a result of decreasing disparity with age. As Figure 3 shows, among the younger age groups the differentials are equally high regardless of moderate or vigorous physical activity.

The physiological consequence of differentials for overeating and a sedentary lifestyle among those with less education result in sizeable disparities with regard to overweight. Among females, the hypothetically least educated are four times more likely to be overweight or obese than are the most educated. ${ }^{3}$ Among men, the least educated are twice as likely to be overweight or obese. However, Figure 5 shows, among men, the differentials decline with age; while among women, they remain constant. Among the younger age groups, the differentials for both sexes are more or less equally high.

Table 3: Odds ratios high versus low educational level, as well as middle versus low level, and the relative index of inequality (RII) for several health behaviors, standardized for age, males and females ages 25-74, Austria, 1999

\begin{tabular}{|c|c|c|c|c|c|c|}
\hline \multirow{3}{*}{ Health behavior } & \multicolumn{4}{|c|}{ Odds Ratio (95\% CI) } & \multirow{2}{*}{\multicolumn{2}{|c|}{ RII $(95 \%$ CI) }} \\
\hline & \multicolumn{2}{|c|}{ Middle vs. Low } & \multicolumn{2}{|c|}{ High vs. Low } & & \\
\hline & \multicolumn{6}{|c|}{ Males } \\
\hline Healthy diet & 1.55 & $(1.42-1.70)$ & 2.82 & $(2.52-3.15)$ & 3.82 & $(3.31-4.41)$ \\
\hline Physical activities & 2.14 & $(1.94-2.36)$ & 4.33 & $(3.82-4.90)$ & 6.55 & $(5.59-7.69)$ \\
\hline Vigorous physical exercise & 1.92 & $(1.69-2.17)$ & 3.33 & $(2.90-3.83)$ & 4.53 & $(3.83-5.37)$ \\
\hline Overweight (BMI > 27) & 1.00 & $(0.91-1.09)$ & 0.61 & $(0.55-0.69)$ & 0.52 & $(0.45-0.60)$ \\
\hline Smoking, age $25-44$ years & 0.77 & $(0.66-0.90)$ & 0.42 & $(0.35-0.50)$ & 0.31 & $(0.24-0.38)$ \\
\hline Smoking, age $45-74$ years & 0.83 & $(0.74-0.95)$ & 0.53 & $(0.44-0.63)$ & 0.47 & $(0.38-0.59)$ \\
\hline $\begin{array}{l}\text { Vacc. polio \& tetanus \& } \\
\text { meningitis }\end{array}$ & 1.93 & $(1.73-2.14)$ & 3.29 & $(2.91-3.72)$ & 4.53 & $(3.88-5.29)$ \\
\hline \multirow[t]{2}{*}{ Vaccinated against influenza } & 1.32 & $(1.15-1.51)$ & 1.56 & $(1.32-1.83)$ & 1.75 & $(1.42-2.15)$ \\
\hline & \multicolumn{6}{|c|}{ Females } \\
\hline Healthy diet & 1.79 & $(1.66-1.93)$ & 2.87 & $(2.59-3.18)$ & 4.36 & $(3.81-4.98)$ \\
\hline Physical activities & 2.20 & $(2.02-2.39)$ & 3.55 & $(3.17-3.98)$ & 6.22 & $(5.35-7.24)$ \\
\hline Vigorous physical exercise & 1.67 & $(1.50-1.87)$ & 2.43 & $(2.14-2.76)$ & 3.47 & $(2.91-4.15)$ \\
\hline Overweight (BMI > 27) & 0.57 & $(0.52-0.61)$ & 0.36 & $(0.32-0.40)$ & 0.24 & $(0.21-0.27)$ \\
\hline Smoking, age $25-44$ years & 0.78 & $(0.69-0.88)$ & 0.49 & $(0.42-0.57)$ & 0.39 & $(0.31-0.48)$ \\
\hline Smoking, age 45-74 years & 1.45 & $(1.26-1.66)$ & 1.48 & $(1.22-1.80)$ & 1.94 & $(1.52-2.47)$ \\
\hline $\begin{array}{l}\text { Vacc. polio \& tetanus \& } \\
\text { meningitis }\end{array}$ & 1.83 & $(1.69-1.99)$ & 2.52 & $(2.27-2.80)$ & 3.81 & $(3.31-4.38)$ \\
\hline Vaccinated against influenza & 1.43 & $(1.28-1.60)$ & 1.54 & $(1.33-1.78)$ & 1.95 & $(1.61-2.36)$ \\
\hline
\end{tabular}

With regard to smoking, the age groups $25-44$ and 45-74 are considered separately because of the interaction with age, as Figure 6 shows. The inequalities for smoking are

\footnotetext{
${ }^{3}$ The odds ratio is symmetric. Hence, the inverse of the odds ratio simply switches the compared categories. For instance, an odds ratio of 0.24 for the most versus the least educated results in an odds ratio of $1 / 0.24=4.17$ for the least versus the most educated.
} 
striking among the younger age group. Here, the odds ratio between the hypothetically most and least educated is 0.31 among males and 0.39 among females. The least educated males are therefore three times more likely to smoke cigarettes on a daily basis than are the most educated males. Among males negative differentials also were found for the age group 45-74, while among females the disparities are reversed, resulting in higher odds for smoking among more highly educated females.

Sizeable differentials were also found for vaccination rates. With regard to people immunized against polio, tetanus and tick meningitis as a single variable, the hypothetically most educated are around four times more likely to be vaccinated compared to those with the least education, regardless of gender. For flu shots, the RII is $1.75 \mathrm{among}$ men and 1.95 among females, averaged over their entire age span. If the older age groups were considered separately, the odds ratios would be much greater, since the differentials increase with age - as Figure 7 shows.

\section{Discussion}

Schwarz $(2005,2006 \mathrm{a}, 2006 \mathrm{~b})$ has shown that the magnitude of educational mortality inequalities is substantial in Austria and affects both men and women. Chapter 2 of the present paper introduced possible explanations for these disparities, namely the cultural/behavioral, material/structural, selection, and artifact approaches. The findings of the present chapter delivers strong evidence for the hypothesis that educational disparities in health behavior are likely to be the main causal factor for the observed mortality differentials. Education exerts a great positive impact on healthy lifestyle with regard to diet, physical exercise, and smoking. The prevalence of overweight decreases significantly with a person's level of education; and people with more education are much more likely to be vaccinated compared to those with the less education.

The variables chosen in this study as a measure of health behavior are well known for their effect on health. Many studies have demonstrated how smoking, unhealthy diet, and a sedentary lifestyle are bad for a person's health (Smith 1993). The physiological consequence of overeating and lack of exercise is a high Body Mass Index (BMI), i.e. overweight. Hence, in most cases, the BMI will indicate the presence of risky behaviors with regard to diet and physical activities. In general, the BMI correlates with the presence of body fat. Because too much body fat often results in chronic diseases such as diabetes and cardiovascular and cerebrovascular diseases, the BMI can also be considered as an indicator of health risk (World Health Organization 2003). Vaccinations are another good indicator for determining how much people care about their health. Those who get their immunizations against very dangerous diseases are probably also aware of other important health issues, such as the preventive value of physical exams.

However, besides differentials in health behavior, also partly responsible for the observed differentials in mortality might be health-damaging material living conditions and physiological and psychological factors associated with social status/class. Another explanation concerns selection and implies that a lower socioeconomic status does not make people less healthy but rather that their socioeconomic status will be lower precisely 
because of their bad health. Longitudinal studies, however, have shown that health selection will account for only a small portion of all health differentials (Davey Smith et al. 1994, Marmot et al. 1998).

The artifact hypothesis, on the other hand, makes aware of possible measurement problems. In the present study, health behavior is self reported, which may cause a bias. Another issue that concerns measurement is the cross-sectional design of this study. It makes it impossible to consider the mutual relationship between health, health behaviors, and education, and it does not allow for any insight into the complex interrelations between causal factors, as is shown in Figure 1, Chapter 2. Thus, it is not possible to precisely determine how much disparities in health behavior contribute to health and mortality differentials, how much are due to health-damaging material living conditions and physiological and psychological factors, and how much is due to health selection. However, each of the single behavioral variables examined in this study provides evidence of the relevance of educational disparities in health behavior and the resulting health differentials.

Schwarz (2006a, 2006b) raises in his papers on cause-specific mortality differentials the issue of the major connection between socioeconomic equalities and public health. Any improvement in health behavior among disadvantaged groups will probably result in a reduction of their high mortality rates and disease prevalence. This means a potential improvement in the population's average health status. Efforts to increase overall population health can directly focus either on health behaviors or on social disparities and their causes. Marmot (1998) talks about an "upstream" and "downstream" focus. A downstream focus concentrates on reducing such negative health behaviors as smoking. In contrast, an upstream focus concentrates on reducing social inequality and its causes, rather than on smoking.

One important upstream focus would be to concentrate on education. Education is a good indicator of social class (Preston and Elo 1995, Davey Smith 1998) and a strong predictor of health behavior and health. An increased proportion of more highly educated people and a smaller proportion of the less educated may therefore improve average overall health status of a population. However, it can also increase educational health differentials, since the relative position of those with less education could worsen when they become an even smaller disadvantaged group. Spielauer et al. (2004) have shown that, in Austria, a person's education is strongly related to that of the parents. It shows that a free and equally accessible educational system does not necessarily guarantee equal opportunity for educational success. This would also mean that an upstream focus concentrating on education would have to start very early in life, e.g. from the pre-school level.

Marmot (1998) also discusses a "more upstream focus" that points to social disparities in health behavior and the fact that people from different social classes benefit differently from health policies. Thus, such policies should take into account the social distribution of a particular health behavior, e.g. smoking (Marmot et al. 1998). 
Nevertheless, regardless of upstream focus, downstream focus, or a combination of them, if nothing changes with regard to socioeconomic disparities in health behavior, the observed mortality differentials are not going to disappear any time soon. In fact, they may increase even further. 


\section{References}

Blakely, T., Fawcett, J., Atkinson, J., Tobias, M. and Cheung, J. 2005. Decades of Disparity II: Socioeconomic mortality trends in New Zealand, 1981-1999. Public Health Intelligence Occasional Bulletin 25. New Zealand: Ministry of Health.

Davey Smith, G. 1990. The black report on socioeconomic inequalities in health ten years on. $B M J, 301$, pp. 373-377.

Davey Smith, G., Blane, D. and Bartley, M. 1994. Explanations for socioeconomic differentials in mortality. Evidence from Britain and elsewhere. European Journal of Public Health, 4, pp. 131-144.

Davey Smith, G., et al. 1998. Educational and occupational social class: which is the more important indicator of mortality risk? Journal of Epidemiology and Community Health, 52, pp. 153-190.

Doblhammer, G. 1997. Socioeconomic differentials in Austrian adult mortality. A study based on linked census and death records for the years 1981/82. $\mathrm{PhD}$ Thesis. Institut für Statistik. University of Vienna

Doblhammer, G., Rau, R. and Kytir, J. 2005. Trends in educational and occupational differentials in all-cause mortality in Austria between 1981/82 and 1991/92. Wiener Klinische Wochenschrift. The Middle European Journal of Medicine, 117(13-14), pp. 468-479.

Kitagawa, E. M. and Hauser, P. M. 1973. Differential Mortality in the United States. A Study in Socioeconomic Epidemiology, Cambridge: Harvard University Press.

Kunst, A. E. 1997. Cross-national comparisons of socio-economic differences in mortality. $\mathrm{PhD}$ Thesis. Erasmus University Rotterdam

Kunst, A. E. and Mackenbach, J. P. 1994. Measuring Socioeconomic Inequalities in Health. Copenhagen: WHO Regional Office for Europe.

Macintyre, S. 1997. The black report and beyond what are the issues? Social Science \& Medicine, 44, pp. 723-745.

Mackenbach, J. P. 2006. Health Inequalities: Europe in Profile. Rotterdam: Department of Public Health at Erasmus MC.

Mackenbach, J. P., et al. 2003. Widening socioeconomic inequalities in mortality in six Western European countries. International Journal of Epidemiology, 32, pp. 830837.

Marmot, M. G., Fuhrer, R., Ettner, S. L., Marks, N. F., Bumpass, L. L. and Ryff, C. D. 1998. Contribution of Psychological Factors to Socioeconomic Differences in Health. The Milbank Quarterly. A Journal of Public Health and Health Care Policy, 76(3), pp. 403-448.

Pamuk, E. R. 1985. Social Class Inequality in Mortality from 1921 to 1972 in England and Wales. Population Studies, 39, pp. 17-31.

Preston, S. H. and Elo, I. T. 1995. Are Educational Differentials in Adult Mortality Increasing in the United States. Journal of Aging and Health, 7(4), pp. 476-496.

Rau, R., Doblhammer, G., Romo, V. C. and Zhang, Z. 2006. Which Causes of Death Contribute to the Widening Gap in Socioeconomic Inequalities in Austrian Adult Male Mortality? : Max Planck Institute for Demographic Research. 
Schwarz, F. 2005. Widening educational differentials in mortality: Analysis for Austria with international comparisons. VID Working paper 07/2005. Vienna: Vienna Institute of Demography, Austrian Academy of Sciences.

Schwarz, F. 2006a. Cause-specific contributions to educational mortality differentials in Austria. Vienna: Vienna Institute of Demography, Austrian Academy of Sciences.

Schwarz, F. 2006b. The contributions of diseases to increasing educational mortality differentials in Austria. Vienna Institute of Demography, Academy of Sciences.

Smith, D. W. G. 1993. Human Longevity, Oxford University Press.

Spielauer, M., Schwarz, F., Städtner, K. and Schmid, K. 2004. Education and Family. Intergenerational educational transmission within families and the influence of education on partner choice and fertility. Research Report. Vienna: Austrian Institute for Family Studies.

Townsend, P. and Davidson, N. 1982. Inequalities in Health: The Black Report, Penguin Books.

Valkonen, T. 2001. Trends in differentials mortality in European countries. In Vallin, J., Meslé, F. and Valkonen, T. (Eds.) Trends in mortality and differential mortality. Strasbourg: Council of Europe Publishing.

World Health Organization. 2003. Information sheet on obesity and overweight. 


\section{VIENNA INSTITUTE OF DEMOGRAPHY}

\section{Working Papers}

Franz Schwarz. The Contributions of Diseases to Increasing Educational Mortality Differential in Austria. VID Working Papers 02/2006. Vienna: Vienna Institute of Demography.

Anne Goujon, Vegard Skirbekk, Katrin Fliegenschnee and Pawel Strzelecki. New Times, Old Beliefs: Projecting the Future Size of Religions in Austria. VID Working Papers 01/2006. Vienna: Vienna Institute of Demography.

Dalkhat M. Ediev. Long-Term Effects of Childbearing Postponement. VID Working Papers 09/2005. Vienna: Vienna Institute of Demography.

Dimiter Philipov, Zsolt Spéder, and Francesco C. Billari. Now or Later? Fertility Intentions in Bulgaria and Hungary and the Impact of Anomie and Social Capital. VID Working Papers 08/2005. Vienna: Vienna Institute of Demography.

Franz Schwarz. Widening Educational Differentials in Mortality: Analysis for Austria with International Comparisons. VID Working Papers 07/2005. Vienna: Vienna Institute of Demography.

Kim, Jungho, Henriette Engelhardt, Alexia Prskawetz, and Arnstein Aassve. Does Fertility Decrease the Welfare of Households? An Analysis of Poverty Dynamics and Fertility in Indonesia. VID Working Papers 06/2005. Vienna: Vienna Institute of Demography.

Kim, Jungho. Women's Education in the Fertility Transition: The Reversal of the Relationship Between Women's Education and Birth Spacing in Indonesia. VID Working Papers 05/2005. Vienna: Vienna Institute of Demography.

Kim, Jungho. Learning by Doing and Learning from Others in Contraceptive Technology. VID Working Papers 04/2005. Vienna: Vienna Institute of Demography.

Heiland, Frank, Alexia Prskawetz, and Warren C. Sanderson. Do the MoreEducated Prefere Smaller Families? VID Working Papers 03/2005. Vienna: Vienna Institute of Demography. 